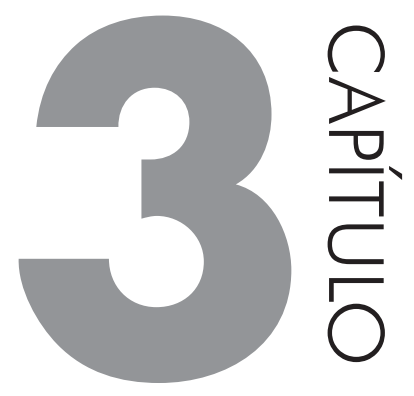

\title{
O PERFIL MULTILÍNGUE DE MOÇAMBIQUE
}

KAREN CRISTINA DA SILVA PISSURNO

\section{INTRODUÇÃO}

Para que se realize um estudo minimamente fiel da variedade de Português falada em Moçambique, faz-se necessário o conhecimento da realidade linguística do país, que difere, e muito, da brasileira e da europeia. A situação de contato linguístico, característica mais especificamente encontrada em algumas variedades africanas, por conta do uso simultâneo de línguas autóctones, como é o caso de Moçambique, iniciado desde sua colonização e ainda muito presente na comunidade, é um quadro fundamental, que atua invariavelmente na construção da variedade moçambicana da Língua Portuguesa.

Em termos geográficos, é importante destacar que Moçambique é um país localizado no Sudeste africano, com extensão territorial de $801.537 \mathrm{~km}^{2}$, dividido em 11 províncias: Niassa, Cabo Delgado, Nampula, Zambézia, Tete, Manica, Sofala, Inhambane, Gaza, Maputo e a cidade de Maputo, capital do país (Cf. Figura 1). Em cada uma dessas províncias fala-se a língua oficial do país, o Português, e ao menos, uma língua Banto específica daquela região. 


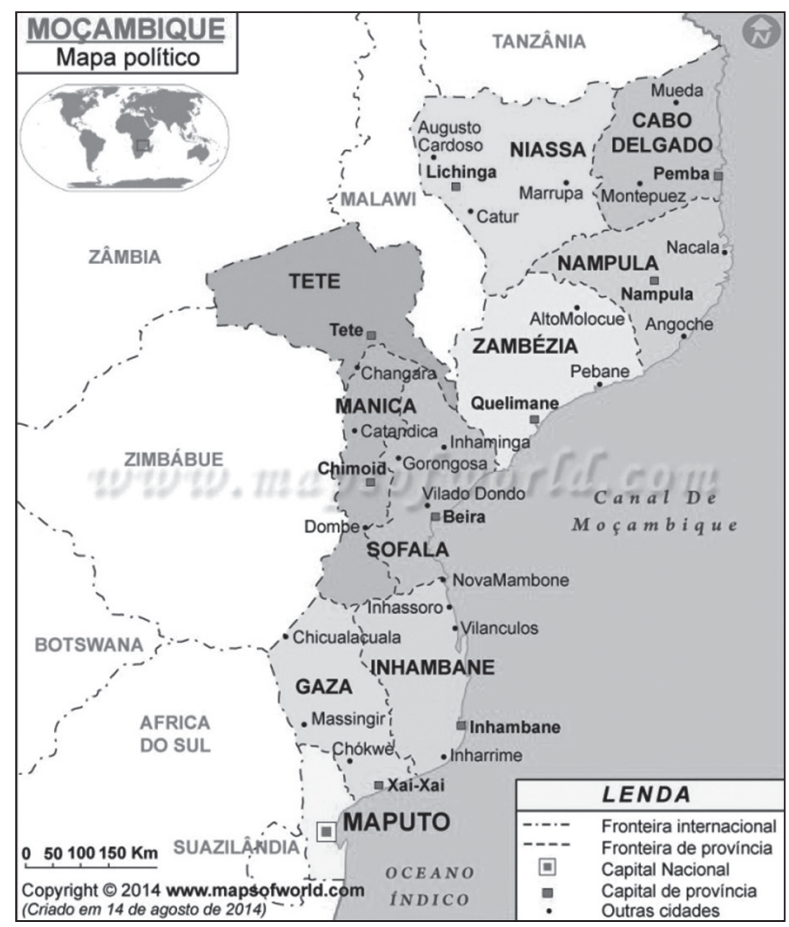

Figura 1 Mapa de Moçambique

Fonte: Disponível em: <https: //pt.mapsofworld.com/mozambique>

Ressalte-se que, todavia, a difusão da Língua Portuguesa pelos colonizadores portugueses nas províncias moçambicanas foi mais lenta do que no Brasil e na Índia, já que, apesar de terem chegado às terras africanas na mesma época em que as colonizavam, em 1498, Moçambique não era prioridade. Assim, o Império Português só foi anexado em 1505 e cerca de 400 anos mais tarde, em 1930, foi estabelecida uma política que tinha por objetivo educar e assimilar culturalmente os africanos, através da introdução do Português como língua de instrução escolar. Somente após a independência do país, em 1975, o Português é definido como língua oficial e passa a ser adotado (e desejado) como a maior, se não a única, fonte de comunicação geral e de transmissão da educação formal.

No entanto, mesmo depois de ser estabelecida como língua oficial do país, dados de recenseamentos (cf. CENSO, 2007; INE, 2010) e de estudos já realizados sobre a variedade moçambicana (cf. GONÇALVES, 2010; NGUNGA, 2012; TIMBANE, 2015; CHIMBUTANE, 2015; GONÇALVES; CHIMBUTANE, 2015; CAO PONSO, 2016; dentre outros) demonstram que o Português coexiste com uma grande diversidade de línguas autóctones. Esses idiomas, todos pertencentes à família Banto, são, para muitos habitantes das áreas rurais de Moçambique, especialmente aqueles acima dos 50 anos de idade, suas línguas maternas. 
Os mais jovens da área rural, por sua vez, assim como os mais velhos, também têm algumas dessas línguas autóctones como maternas. Sendo assim, o idioma tido como oficial apresenta um status de língua estrangeira $(\mathrm{LE})^{1}$ para esses indivíduos, ou seja, uma língua utilizada em situações bastante artificiais, especialmente instrucionais, já que a língua alvo só é aprendida em contextos de educação formal, enquanto em casa os indivíduos utilizam suas línguas maternas para comunicação diária.

Por outro lado, nas áreas urbanas, a situação é similar à do uso de uma segunda língua (L2), ou seja, a exposição à língua alvo não se faz apenas em contexto escolar, mas é exigida em praticamente todos os ambientes nos quais os indivíduos estabelecem comunicação, já que, mesmo que dentro de casa eles falem sua língua materna, fora dela é necessário comunicar-se exclusivamente em outra língua, que não sua L1. No caso de Moçambique, para além do uso das línguas autóctones, a população tem contato intenso com o Português no seu dia-a-dia e nos ambientes que frequenta e, consequentemente, as crianças já chegam à escola com conhecimento prévio da língua. Da mesma forma, aqueles que nascem em famílias que afirmam usar somente o Português dentro de casa tendem a adquiri-lo como sua primeira língua (L1) e, igualmente, entram na escola já com conhecimento da modalidade oral do idioma. Assim, nas áreas urbanas, independentemente da idade do indivíduo, o acesso ao Português é mais fácil e constante, permitindo o contato desde muito cedo com essa língua, o que facilita sua aquisição.

Em termos gerais, portanto, pode-se dizer que o povo moçambicano, é, em sua grande maioria, pelo menos, bilíngue. O Censo 2007 corrobora essa afirmação, já que registra o Português como a língua mais utilizada por seus habitantes dentro de casa, especialmente aqueles que vivem nas áreas urbanas. Já os que vivem nas áreas rurais, por outro lado, têm na educação formal o único meio de contato com a Língua Portuguesa, fato diretamente relacionado às altas taxas de analfabetismo dos habitantes mais velhos, que continuam a utilizar as línguas Banto faladas no país.

1 Basicamente, a diferença entre aquisição de segunda língua (L2) e de língua estrangeira (LE) está relacionada, principalmente, aos contextos nos quais as línguas são aprendidas. De acordo com Stern (1983), segunda língua está relacionada ao aprendizado e o uso de uma língua, diferente da materna, dentro de um território no qual ela exerce uma função social e/ou política. Por outro lado, uma língua estrangeira seria usada em espaços nos quais não haveria um estatuto sociopolítico que exigisse o uso da mesma. Assim, entende-se que a população rural de Moçambique não utiliza a Língua Portuguesa nos contextos que lhes são mais íntimos e familiares, pois não há exigência de uso deste idioma. Sendo assim, seu uso fica restrito às áreas nas quais o Português é a principal língua de comunicação (na cidade, nas escolas, etc.), como uma LE. Para mais informações sobre a distinção entre LE x L2, cf. Krashen (1982). 
Em suma, a diversidade linguística presente nas comunidades de fala moçambicanas constitui um aspecto cultural muito relevante e tem relação direta com a questão educacional e a transmissão da Língua Portuguesa. Assim, é imperativo relatar, de forma mais detalhada, como essa diversidade de línguas é distribuída, por motivos históricos e/ou sociais, dentro da sociedade em questão, como se verá a seguir.

\section{DADOS SÓCIO-HISTÓRICOS SOBRE AS LÍNGUAS MOÇAMBICANAS}

Considerando, à priori, os principais perfis de falantes de Português (L2 x LE) presentes em Moçambique, estabelecem-se duas situações: de um lado, encontram-se os habitantes das zonas mais rurais, que possuem línguas Banto como L1 e que, teoricamente, recebem a transmissão do Português Europeu (PE) considerado padrão, como uma LE, em contextos descontinuados, formalizados apenas para os habitantes mais jovens quando em ambiente escolar; de outro lado, temos os habitantes das áreas urbanas, que têm acesso à língua em todos os seus ambientes de uso (na família, na escola e no trabalho), haja vista o valor concedido à língua oficial do país, que possibilita a ascensão social de seus usuários. Nesse caso, diversas crianças adquirem o Português como L1 (ou como uma L2 em paralelo - ou não - a uma língua autóctone), transmitido por seus pais dentro de casa e, supostamente, aprimorado na escola. A aquisição de língua para esses indivíduos, portanto, poderia atingir níveis de conhecimento parecidos com os dos falantes de PE, por exemplo, que não passam por processos semelhantes de contato com outras línguas.

Salientam-se aqui, de maneira bem breve, três fatos bastante relevantes em relação ao quadro linguístico ora apresentado: i) os pais dessas crianças, assim como alguns de seus professores, não são, necessariamente, falantes nativos de Português, o que nos leva a questionar qual "modelo" de língua lhes está sendo transmitido; ii) a importância social dada à Língua Portuguesa é salutar nessa comunidade de fala, assim como em São Tomé e Príncipe (cf. BRANDÃO; VIEIRA, 2012a; 2012b), já que seu domínio é associado ao prestígio e à ascensão econômica, desencadeando o desejo de muitos pela sua aquisição em detrimento do uso das línguas autóctones; iii) ao lado da parcela crescente de indivíduos que deseja adquirir a Língua Portuguesa e que acredita que saber (ou dizer que sabe) uma língua local pode atrapalhar suas chances de ascender socialmente, estão aqueles indivíduos, especialmente das zonas rurais, que não deixam de usar seus idiomas maternos, por seu significado afetivo e cultural.

Sendo assim, mesmo que a população reconheça o valor altamente prestigioso do Português no país, as línguas autóctones, invariavelmente presentes na rea- 
lidade de todos (em maior ou menor grau), nunca chegaram a ser totalmente eliminadas e a crescente migração para a cidade faz reavivar o uso desses idiomas também dentro da cidade, nos ambientes mais diversos, sobretudo os informais. O resultado, portanto, é o uso simultâneo das diversas línguas na sociedade, que tende a selecionar os contextos em que cada uma delas tem maior valor.

Observando-se a distribuição da população de mais de 20 milhões de habitantes, que tem como língua oficial o Português, mas que, ao mesmo tempo, tem contato direto ou indireto com as mais de 20 línguas Banto (SITOE; NGUNGA, 2000 apud GONÇALVES, 2010, p. 25) e cinco línguas asiáticas presentes no país, confirma-se o caráter plurilíngue dessa sociedade. A tabela a seguir apresenta a relação dessas línguas, por número de falantes e províncias onde são faladas.

Tabela 1 Línguas faladas pela população de 5 ou mais anos de idade

\begin{tabular}{|c|l|c|c|l|}
\hline $\mathbf{N}^{\circ}$ & \multicolumn{1}{|c|}{ LíNGUA } & N DE FALANTES & $\%$ & \multicolumn{1}{|c|}{ PRovíncIAS } \\
\hline 1 & Makhuwa & 4.105 .122 & 25.92 & Cabo Delgado, Nampula, Niassa, Zambézia, Sofala \\
\hline 2 & Português & 1.828 .239 & 11.54 & Todas as províncias \\
\hline 3 & Changana & 1.682 .438 & 10.62 & Gaza, Maputo, Maputo City, Inhambane, Niassa \\
\hline 4 & Sena & 1.314 .190 & 8.30 & Manica, Sofala, Tete, Zambézia \\
\hline 5 & Lomwe & 1.202 .256 & 7.59 & Napula, Niassa, Zambézia \\
\hline 6 & Chuwabu & 989.579 & 6.24 & Sofala, Zambézia \\
\hline 7 & Nyanja & 905.062 & 7.71 & Niassa, Tete, Zambézia \\
\hline 8 & Ndau & 702.455 & 4.43 & Manica, Sofala \\
\hline 9 & Tshwa & 469.343 & 2.96 & Gaza, Inhambane, Maputo, Sofala \\
\hline 10 & Nyungwe & 457.290 & 2.88 & Manica, Tete \\
\hline 11 & Yaawo & 340.204 & 2.14 & Cabo Delgado, Niassa \\
\hline 12 & Makonde & 268.450 & 1.69 & Cabo Delgado \\
\hline 13 & Tewe & 255.704 & 1.61 & Manica \\
\hline 14 & Rhonga & 239.333 & 1.52 & Gaza, Maputo, Maputo City, Inhambane \\
\hline
\end{tabular}




\begin{tabular}{|c|l|c|c|l|}
\hline 15 & Tonga & 203.924 & 1.38 & Gaza, Maputo, Maputo City, Inhambane \\
\hline 16 & Copi & 169.811 & 1.07 & Gaza, Maputo, Maputo City, Inhambane \\
\hline 17 & Manyika & 133.190 & 0.84 & Manica \\
\hline 18 & Cibalke & 102.778 & 0.64 & Manica \\
\hline 19 & Mwani & 77.915 & 0.49 & Cabo Delgado \\
\hline 20 & Koti & 60.780 & 0.38 & Nampula \\
\hline 21 & Swahili & 15.250 & 0.10 & Cabo Delgado \\
\hline 22 & Outras & 310.259 & 1.95 & Todas as províncias \\
\hline 23 & Línguas de sinais & 7.059 & 0.05 & Todas as províncias \\
\hline Total & & $\mathbf{1 5 . 8 3 3 . 5 7 2}$ & $\mathbf{1 0 0}$ & \\
\hline
\end{tabular}

Fonte: Censo de $2007^{2}$

Em síntese, podem-se destacar as seguintes línguas como concorrentes do Português na cidade de Maputo, capital do país: Changana, Tshwa, Rhonga, Tonga, Copi. Como revelam os dados extraídos do Censo $2007^{3}$, as línguas que coexistem com o Português em Maputo não são muito expressivas em se tratando de L1, sendo que a mais utilizada é a chamada Changana, falada por $31,5 \%$ da população. Vê-se, portanto, que a percentagem de habitantes que afirma usar preferencialmente o Português é bastante superior $(42,9 \%)$ e aumentou em comparação com o Censo de 1997, que registrava 39,5\% e assinalava o Português como a L1 de apenas 6,5\% dos falantes. (cf. GONÇALVES, 2010, p. 26).

Essa diferença percentual pode ter uma de suas explicações na questão da faixa etária dos informantes do Censo, uma vez que, como a própria autora

2 Tabela disponível em: <http: //www.site.letras.ufmg.br/laliafro/projeto.html>. Acesso em: 11 de fevereiro de 2017.

3 Cabe salientar que os métodos de coleta de dados para o Censo de Moçambique são recentes, tendo até o momento apenas 2 registros formais (1997, 2007). Isto nos leva a crer que é preciso cuidado ao observar os dados apresentados nas tabelas, que podem conter alguns números ainda questionáveis. Charles; Sá (2010) e Charles (2012) mencionam a necessidade de atualização das cartas geográficas que auxiliariam o processo de coleta de dados para os censos e os inquéritos feitos em Moçambique, fazendo com que seus resultados sejam mais precisos de acordo com a realidade do país. 
afirma, "os índices mais elevados de conhecimento dessas línguas verificam-se entre os recenseados com mais de 25 anos" (GONÇALVES, 2010, p. 27). Isso quer dizer que, ao longo dos 10 anos que se passaram entre os recenseamentos, a formação de novas crianças, especialmente nas cidades em que o Português é a língua principal, não somente de instrução escolar, mas de uso na grande maioria dos contextos comunicativos, pode ter ajudado consubstancialmente a aumentar a quantidade de falantes da Língua Portuguesa na zona urbana de Moçambique como um todo, que hoje apresenta $10,7 \%$ de falantes de Português como L1, de acordo com o INE 2010, que compara a distribuição de língua materna de 1980 a 2007. Como se vê na tabela a seguir, o percentual de indivíduos que se declaram como falantes de línguas Banto como L1 vai se reduzindo proporcionalmente ao aumento de declarantes de Português como língua materna em todo o país:

Tabela 2 Distribuição percentual da população de 5 anos ou mais anos de idade, segundo língua materna em Moçambique, em 1980, 1997 e 2007

\begin{tabular}{|c|c|c|c|c|c|c|}
\hline $\begin{array}{c}\text { ANO DO } \\
\text { CENSO }\end{array}$ & $\begin{array}{c}\text { LÍNGUA } \\
\text { BANTO }\end{array}$ & PORTUGUÊS & $\begin{array}{c}\text { OUTRAS } \\
\text { LÍNGUAS } \\
\text { ESTRANGEIRAS }\end{array}$ & MUDO & NENHUMA & DESCONHECIDA \\
\hline 1980 & 98.8 & 1.2 & - & - & - & - \\
\hline 1997 & 93.0 & 6.5 & 0.4 & 0.02 & 0.06 & 1.0 \\
\hline 2007 & 85.2 & 10.7 & 0.4 & 0.04 & 0.01 & 3.6 \\
\hline
\end{tabular}

Fonte: INE (2010) sobre Censos de 1980, 1997 e 2007

Timbane (2015), seguindo a mesma linha de pensamento, ratifica que "o número de falantes de português tende a crescer desde 1980 (5 anos após a proclamação da independência) incentivado pela educação massiva e inclusiva principalmente nas zonas urbanas" (TIMBANE, 2015, p. 295), que ocorreu tardiamente em Moçambique.

Além disso, segundo Firmino (1988),

O maior envolvimento, a todos os níveis, dos moçambicanos na acção pública (instâncias do poder, serviços públicos, comércios, etc.), o aumento das situações de comunicação em que os interlocutores não falam a mesma língua bantu [...] o aumento da população escolar atingindo níveis cada vez mais altos, são alguns dos factores que justificam a subida do número de falantes da língua portuguesa. (FIRMINO, 1988, p. 98) 
Em outras palavras, a Língua Portuguesa foi, aos poucos, transformando-se na língua de comunicação básica dos moçambicanos, satisfazendo as necessidades de comunicação para obtenção de todos os tipos de serviços, especialmente nas áreas urbanas e na educação escolar, que privilegia o Português como a língua de prestígio, cujo domínio possibilita ascensão social, enquanto não dominá-la significa possibilidades de exclusão social e de preconceitos.

Timbane (2015) corrobora essas afirmações, ao atestar que

O português é uma língua moçambicana de origem europeia porque ela já satisfaz as necessidades comunicativas dos moçambicanos e já tem falantes nativos. Toda a educação formal é feita em português pelo fato de ser a língua de prestígio, por ser oficial e ser amparada pela Constituição da República de Moçambique (2004), instrumento que não dá relevância às diversas línguas bantu moçambicanas faladas pela maioria da população. (TIMBANE, 2015, p. 295)

No entanto, a população da zona rural continua tendo o Português praticamente como uma língua estrangeira, de acesso restrito ao meio escolar. Fora da escola, não há meios de difusão que permitam aos moçambicanos dessas áreas o domínio da língua de prestígio da sociedade. Menezes (2013), mencionando estudos sociolinguísticos e números do INE de 1997, com relação à área de residência em Moçambique, destaca que

os que sabem falar português nas zonas urbanas equivalem a uma percentagem de $72.4 \%$ e, nas zonas rurais, $25.4 \%$ [...], enquanto os que têm português como língua materna equivalem a $17 \%$ nas zonas urbanas e $2 \%$ nas rurais. (MENEZES, 2013, p. 38)

Já o Censo de 2007 destaca que apenas 3.5\% da população rural declara ter o Português como L1. Em outras palavras, pode-se dizer que, apesar da larga expansão da Língua Portuguesa em todo o país, o número de pessoas que tem o Português como L1 é ínfimo, especialmente por conta do grande número de pessoas que utilizam as línguas Banto nas áreas rurais.

Chimbutane (2012) confirma esse cenário, ao informar que tais dados podem

[...] ser reflexo de uma extraordinária expansão da língua portuguesa pelos meios urbanos, ao mesmo tempo que pode indicar que, apesar do crescimento da percentagem de habitantes de áreas rurais que sabem falar a língua portuguesa, estes preferem falar as línguas bantu na sua comunicação em casa. (CHIMBUTANE, 2012, p. 26)

De acordo com Gonçalves (2010), a complexidade da situação linguística do país pode ser mais bem compreendida a partir do entendimento do processo his- 
tórico desde a chegada dos colonos portugueses em 1498. Apesar de terem chegado ao país na mesma época em que colonizavam o Brasil e a Índia, Moçambique não era o foco de suas atenções e, consequentemente, a difusão da Língua Portuguesa foi mais lenta. Sendo assim, houve uma considerável demora para a criação de políticas educacionais e, então, apenas em 1930 é estabelecida uma política, na qual o Português se torna a língua de instrução escolar, com o objetivo de educar e permitir a assimilação cultural dos africanos, deixando as línguas nacionais para uso exclusivo em contextos familiares e de instrução religiosa.

Nas palavras de Gonçalves:

Em consequência do atraso no processo de colonização de Moçambique em que sobressai a criação tardia de uma rede escolar a nível nacional - na altura da independência, em 1975, a língua portuguesa era parte do repertório linguístico de um grupo minoritário de moçambicanos, residentes principalmente nos centros urbanos. (GONÇALVES, 2010, p. 31)

Dessa maneira, entende-se que a transmissão da Língua Portuguesa aos moçambicanos aconteceu de maneira progressiva e tardia, permitindo àqueles que tinham acesso à escola a aquisição do Português como L2 em contextos formais, enquanto os mais velhos, que não tiveram acesso à escola e são residentes das zonas rurais, permanecem utilizando suas línguas maternas Banto para comunicação natural e diária.

Após a independência do país, o Português é definido como língua oficial, tomando totalmente o lugar das línguas Banto, já que passa a ser apontada como mais eficaz para a comunicação internacional e a transmissão de conhecimentos, além de ser considerada, cada vez mais, como língua de prestígio e que permitiria ascensão social aos seus falantes. Desse modo, o Português ganha novos valores tanto para aqueles que já o dominam quanto para aqueles que desejam dominá-lo.

Advindo dessa mudança de valores, a população que frequenta a escola passou por um processo de grande crescimento, tendo, de acordo com o Censo de 2007, mais de 5 milhões de alunos. Tal número reflete a multiplicação do número de falantes da Língua Portuguesa e a importância cada vez maior facultada a ela. Gonçalves ainda assegura que

as classes mais favorecidas dos centros urbanos têm tendência a comunicar entre si exclusivamente em português (ainda que este não seja a sua L1), sendo a língua escolhida para transmitir às novas gerações. (GONÇALVES, 2010, p. 34).

Cabe ressaltar que, ao longo do período colonial, nas zonas rurais, a população continuava a se comunicar em suas línguas Banto e a transmiti-las para as 
novas gerações, enquanto o Português era adquirido apenas como LE. O contato com o Português era restrito, então, à instrução formal e religiosa, e a textos escritos, de onde vinha o input mais estruturado possível para esses falantes. Portanto, pode-se concluir que grande parte dos falantes de Português hoje o tem como uma L2 (nas zonas urbanas) ou uma LE (nas zonas rurais), o que, consequentemente, gera "variabilidade das regras e traços gramaticais específicos da sua gramática” (GONÇALVES, 2010, p. 37).

Tal contexto parece sempre ter sido motivo de conflitos para os moçambicanos, especialmente durante o período colonial, pois o valor da Língua Portuguesa era tão alto, que muitas famílias proibiam suas crianças de usarem as línguas locais dentro de casa, forçando-as a utilizar apenas o Português, como declara Rosário (2015):

No tempo colonial, os pais assimilados ${ }^{4}$ castigavam, algumas vezes severamente, os filhos, quando estes aprendiam as línguas africanas com as avós ou com os empregados domésticos. E as razões que apresentavam eram que, ao aprender as línguas africanas, contaminavam o seu Português, e, com isto, envergonhavam os seus pais em momentos de convívio social, por causa da "horrível pronúncia" cafrealizada, ou então porque esse conhecimento dificultava a aprendizagem e a aquisição do saber na escola, e também o desempenho no trabalho. (ROSÁRIO, 2015, p. 24)

A partir dessas crenças, as línguas autóctones foram se tornando estigmas, consideradas como línguas tribais. Aqueles que desejassem algum tipo de ascensão social e prestígio na sociedade precisavam falar Português. No entanto, devido à presença ainda muito forte dessas línguas em outros contextos, era praticamente impossível não adquirir, ainda que de forma discreta, as línguas Banto da comunidade. Assim, criou-se uma geração que, supostamente, só sabia falar Português, mas que, na verdade, nunca deixou de ter algum tipo de contato com as línguas africanas.

Assim, os jovens da minha geração, aprendendo embora as línguas maternas africanas, quer através das suas próprias mães, quer através das avós ou, no caso das famílias mais abastadas, através dos empregados domésticos, mantinham essa competência linguística mais ou menos adormecida, embora lhes fosse útil em momentos apropriados. Grande parte dos cida-

4 Vale explicar que os "assimilados" são assim denominados por serem negros que tentaram, de muitas formas, se aproximar dos hábitos e dos costumes dos portugueses, incluindo, principalmente, o uso da Língua Portuguesa em detrimento das línguas autóctones. Seu objetivo era assimilar o status de civilização dos portugueses para obter condições similares de desenvolvimento educacional e profissional. 
dãos desta geração, sobretudo os grupos das cidades mais importantes, criou a ilusão de que seus filhos não dominavam senão a língua portuguesa. (ROSÁRIO, 2015, p. 24)

Sobre os dias atuais, Chimbutane (2012) resume as tendências de uso das línguas em nível provincial, afirmando que

De modo geral, em todas as províncias, (a) as línguas bantu são as mais frequentemente faladas em casa, (b) o Português tende a ser cada vez mais uma língua falada com frequência no domínio familiar e doméstico." (CHIMBUTANE, 2012, p. 29).

Isto posto, pode-se concluir que, de fato, há um plurilinguismo presente na realidade linguística de Moçambique, na qual existe predominância da Língua Portuguesa nas áreas urbanas, mas ainda há resquícios e indícios de uso dos idiomas da família Banto, principalmente entre os habitantes mais velhos da população, em ambientes domésticos e nas áreas mais rurais do país. Nas palavras de Stroud (1997),

A escolha de uma norma linguística que é externa à nação na qual a língua é falada significa que as instituições oficiais como a escola e outras arenas tais como o mercado de trabalho, acabam por exercer controlo sobre quem terá acesso à língua. Uma consequência deste facto é a criação de certo número de mercados linguísticos, mais ou menos integrados num 'mercado' linguístico oficial na qual os falantes podem aproximar-se da norma (europeia), e a existência simultânea e paralela de alguns mercados linguísticos não oficiais. (STROUD, 1997, p. 28).

Enquanto nas áreas mais urbanas o Português é a principal, quando não a única, língua de comunicação cotidiana, nas áreas mais rurais, por outro lado, o Português funciona como a língua de comunicação comercial, restrita a contextos de LE, convivendo com uma ou mais línguas Banto, devido ao caráter misto da população. Logo, é evidente a natureza variável da Língua Portuguesa falada nessas áreas, que convive em meio a tão intenso contato linguístico. Sendo assim, é difícil até mesmo definir a qual modelo de Português esses indivíduos, em situação tão diversificada, estão tendo acesso de fato e, ainda, quais características específicas dessa heterogeneidade estão sendo repassadas às novas gerações.

\section{O "MODELO" DE PORTUGUÊS FALADO EM MOÇAMBIQUE}

Tal contexto de extrema variabilidade implica a adaptação dos falantes rurais às variadas situações de uso do Português, dispondo, enquanto falantes de uma LE, de menos oportunidades de contato com a língua considerada padrão e 
mais contato com usos não oficiais. Assim, esse cenário pode levar a variação para uma determinada direção, mais ou menos afastada do "modelo" alvo, a saber, o Português Europeu. Já os falantes urbanos, considerando também os mais escolarizados, teriam mais oportunidades de adquirir o Português padrão, à semelhança do $\mathrm{PE}$.

De acordo com Chimbutane (2015), o advento da democratização do país, por volta dos anos 1980, reforçou a perspectiva de um Português padrão a ser alcançado, que excluísse totalmente qualquer característica prototípica de uma Língua Portuguesa que pudesse ser considerada propriamente moçambicana e se aproximasse, cada vez mais, da variedade europeia:

Com efeito, se bem que ainda se preconizasse o desenvolvimento de um Português moçambicano, surge uma preocupação em normalizar esse Português e até mesmo de se ter o padrão europeu como norma escolar. [...] nessa fase a preocupação central já não era a uniformização do Português falado em Moçambique [...] mas a importação de uma norma "exógena", desconhecida pela maioria dos falantes, incluindo pela maior parte dos professores [...] a escola começou a preocupar-se mais com o ensino da gramática, passando a ser menos tolerante em relação a formas "desviantes", incluindo aquelas que outrora eram positivamente recebidas como marcas de moçambicanidade. (CHIMBUTANE, 2015, p. 55-56)

Timbane (2014) critica a existência de um Português padrão similar ao europeu em Moçambique, afirmando que as línguas Banto ainda existem dentro e fora da cidade, sem nenhuma chance de serem totalmente extintas. Para o autor, essa situação de uso simultâneo das línguas reforça a hipótese de que existiria um Português propriamente moçambicano, "nativizado", resultante das mudanças influenciadas pelo contato com as línguas autóctones e que geram variações diferentes do Português Europeu padrão que teria sido seu modelo de formação:

Adotamos o termo nativização [...] para designar o processo de transformação da norma-padrão europeia em PM, uma variedade que na base das LB adapta, integra na língua seus valores culturais, sua identidade, seus símbolos, seus objetos materiais de tal forma que seja sentida como pertence dos moçambicanos. (TIMBANE, 2014, p. 11)

Considerando o uso de um Português padrão, cabe ressaltar a questão social do sexo dos falantes, que parece indicar menor uso da norma de prestígio por parte das mulheres, já que estas teriam a tendência de promover o uso de línguas Banto, devido à sua baixa escolaridade e aos contextos sociais dos quais fazem parte. Ao que tudo indica, mesmo depois da independência do 
país, as mulheres ainda têm menos acesso à educação formal e, consequentemente, à Língua Portuguesa tida como padrão. O mercado de trabalho reforçaria essa postura, haja vista seus deveres fortemente familiares e poucas oportunidades de atividade laboral fora do ambiente familiar, como esclarece Stroud (1997):

[...] embora as mulheres e os homens tenham exatamente a mesma variedade e tipo de redes sociais, os indivíduos do sexo masculino falam um Português mais padrão do que as mulheres, e estas falam melhor as línguas bantu locais que os homens. Uma explicação para isto é que as redes recebem o seu sexo de acordo com a língua; as ocupações que as mulheres têm são mais orientadas para o uso de línguas bantu locais contrariamente aos homens. (STROUD, 1997, p. 33)

No entanto, a comparação entre os Censos de 1997 (que registrava apenas $29 \%$ de mulheres que sabiam falar LP) e 2007 (apresentando o total de 41,6\% na mesma categoria) demonstra estar havendo uma mudança nesse panorama, com claro crescimento no número de mulheres que declaram saber falar Português. Chimbutane (2012) discorre sobre a mudança nesse percentual e a diminuição da disparidade entre os sexos, afirmando que

Esta situação pode dever-se a uma gradual mudança de atitude em relação ao lugar da mulher na sociedade, o que pode ser consequência de diferentes políticas e acções sociais visando a equidade de gênero no país. Em termos específicos, estes dados podem indicar que a mulher tem estado a ter cada vez mais acesso à educação formal, uma das principais vias de aprendizagem da língua portuguesa em Moçambique, em especial nas áreas rurais. (CHIMBUTANE, 2012, p. 18)

Ainda assim, o autor reitera que

[...] as populações das áreas rurais e as mulheres estão numa clara situação de desvantagem em relação às populações das áreas urbanas e ao homem, respectivamente: as populações das áreas rurais e as mulheres registram índices comparativamente mais baixos de conhecimento da língua portuguesa e de alfabetização. (CHIMBUTANE, 2012, p. 43)

Em vista de toda essa desigualdade, ainda presente na sociedade, em relação ao acesso à Língua Portuguesa, seja pela localidade (rural x urbano), pela escolaridade (mais ou menos escolarizados), pela idade (indivíduos mais jovens $\mathrm{x}$ mais velhos) ou até mesmo o sexo (homem x mulher), a partir dos anos 90, o Ministério da Educação institucionalizou o debate sobre a introdução das línguas locais na educação formal. Assim, deu-se início às discussões sobre uma 
educação bilíngue, que vem sendo apoiada por linguistas (cf. CHIMBUTANE, 2015; MENEZES, 2013; NGUNGA, 2007; LOPES, 1997; TIMBANE, 2015) que defendem a necessidade desse tipo de ensino para que, em séries mais avançadas, os alunos consigam desenvolver melhor suas habilidades, haja vista o grande fracasso escolar observado naqueles que não aprenderam Português em casa e só compreendem seus idiomas maternos. No entanto, a sua execução tem encontrado dificuldades em relação ao material didático, à grande quantidade de línguas nas quais os materiais deveriam ser produzidos e aos custos dessa produção, além da incipiente descrição das línguas locais (CHIMBUTANE, 2015).

Em poucas palavras, mesmo com toda a diversidade linguística e a tentativa de introduzir as línguas locais no ensino escolar, a Língua Portuguesa continua sendo a língua de maior prestígio e, mesmo que haja uma valorização das línguas nacionais, estas parecem estar fadadas a um simples papel integrativo, como conclui Chimbutane (2015):

O Português é assumido como um recurso que permite acesso a mercados de trabalho formais e aos dividendos socioeconômicos daí decorrentes, ao passo que as línguas locais são vistas como meros veículos de comunicação familiar ou entre membros de grupos etnolinguísticos específicos. Ou seja, no geral, as línguas locais não são associadas à geração de capital ou percebidas como recursos a explorar em mercados laborais formais. (CHIMBUTANE, 2015, p. 65)

\section{CONSIDERAÇÕES FINAIS}

Pode-se concluir que nem mesmo o ensino bilíngue garante melhores oportunidades de vida para os moçambicanos e que os fatores sociais são de fato relevantes no que tange à caracterização da variedade moçambicana do Português, na medida em que as variantes estigmatizadas, possivelmente decorrentes do constante contato com essas variadas línguas autóctones, não ocorrem de forma aleatória e, portanto, são regularmente estruturadas e podem ser descritas de forma a contribuir com a construção do perfil sociolinguístico desta variedade.

Tendo em vista o contexto ora apresentado, pode-se afirmar, indubitavelmente, o caráter multilíngue da sociedade moçambicana. Diante de tais circunstâncias, o estudo da variedade de Português falada em Moçambique exige que haja o cuidado especial de explorar suas especificidades. Tais propriedades fazem dela uma variedade única, demonstrando tendências semelhantes às de uma variedade ainda em processo de formação, em busca de características próprias que revelam a situação de contato linguístico, que é constante e inseparável de sua 
realidade. Note-se que todo esse cenário não se deve somente aos traços sócio- políticos e culturais que se entrelaçam aos linguísticos, como também ao próprio fato de ser essa uma variedade recentemente aceita como oficial em um país independente apenas há 43 anos.

\section{REFERÊNCIAS}

BRANDÃO, S. F.; VIEIRA, S. R. A concordância verbal e nominal no português do Brasil e no português de São Tomé: uma abordagem sociolinguística. Papia, 22(1): 7-40, 2012 a.

BRANDÃO, S. F.; VIEIRA, S. R. Concordância nominal e verbal: contribuições para o debate sobre o estatuto da variação em três variedades urbanas do português. Alfa, v. 56, n. 3, p. 1035-1064, 2012b.

CAO PONSO, L. O contato entre o Português e as línguas Banto em Moçambique: a alternância de atitudes sobre o estatuto social das línguas em jovens universitários. Cadernos de Letras da UFF: línguas e culturas em contato, n. 53, p. 121-144, 2016.

CHARLES, A. J.; SÁ, L. A. C. M. (Cartografia Censitária de Moçambique. III Simpósio Brasileiro de Ciências Geodésicas e Tecnologias da Geoinformação. 2010. Recife, PE. Disponível em: <https: //www.ufpe.br/cgtg/SIMGEOIII/IIISIMGEO_CD/artigos/CartografiaeSIG/Cartografia/A_10.pdf.> Acesso em: 12 de julho de 2016.

CHARLES, A. J. Proposta metodológica para cartografia censitária de Moçambique. Dissertação de Mestrado. Universidade Federal de Pernambuco. Recife, 2012.

CHIMBUTANE, F. S. Língua e Educação em Moçambique: Uma perspectiva Sócio-Histórica. In: GONÇALVES, P.; CHIMBUTANE, F. S. (Org.). Multilinguismo e Multiculturalismo em Moçambique: em direção a uma coerência entre discurso e prática. Moçambique: Alcance Editores, 2015.

CHIMBUTANE, F. S. O uso da L1 dos alunos como recurso no processo de ensino e aprendizagem de/em Português/L2: o contexto de ensino bilíngue em Moçambique. Revista Científica da Universidade Eduardo Mondlane, Série: Letras e Ciências Sociais, v. 1, n. 1, p. 7-25, 2015.

CHIMbUTANE, F. S. Panorama linguístico de Moçambique: Análise dos dados do III Recenseamento Geral da População e Habitação de 2007. Maputo: Instituto Nacional de Estatística, 2012.

FIRMINO, G. Desvios à norma no português falado em Moçambique. Actas do $4^{\circ}$ encontro da associação portuguesa de linguística, Lisboa, p. 97-106, 1988.

GONÇALVES, P. Tipologia de erros do Português Oral de Maputo: um primeiro diagnóstico. In: GONÇALVES, P.; STROUD, C. (Org.). Panorama do Português oral de Maputo, v. II; A construção de um Banco de "Erros". INDE - Cadernos de Pesquisa n. 24. Maputo: Moçambique, 1997.

GONÇALVES, P. A gênese do Português de Moçambique. Lisboa: INCM, 2010. 
GONÇALVES, P.; CHIMBUTANE, F. S. (Org.). Multilinguismo e Multiculturalismo em Moçambique: em direção a uma coerência entre discurso e prática. Moçambique: Alcance Editores, 2015.

HOLM, J. An Introduction to pidgins and creoles. Cambridge University Press. United Kingdom, 2000.

Instituto Nacional de Estatística. III Recenseamento Geral da População e Habitação - 2007: indicadores sócio-demográficos, Moçambique, Maputo, Instituto Nacional de Estatística, 2010.

JEQUE, A. O enfraquecimento da morfologia flexional verbal (pessoa e número) no português de Moçambique. Tese (Licenciatura) - Universidade Eduardo Mondlane, Moçambique, 1996.

JON-AND, A. Variação, contato e mudança linguística em Moçambique e Cabo Verde. A concordância variável de número em sintagmas nominais do português. Dissertação (Doutorado) - Stockholm University, Suécia, 2011.

JUSTINO, V. Concordância verbal em número: da descrição linguística à avaliação no contexto de ensino-aprendizagem. In: BASTOS, M.; MARQUES, J.; MONTEIRO, A.; SIOPA, C. (Org.). Ensinar a lingua portuguesa em Moçambique: desafios, possibilidades e constrangimentos. Textos selecionados das VII Jornadas da Língua Portuguesa, p. 166 186. Porto: Porto Editora, 2015a.

KRASHEN, S. D. Principles and Practice in Second Language Acquisition. Oxford: Pergamon Press, 1982.

LOPES, A. J. Política Linguística: princípios e problemas. Maputo: Imprensa Universitária, 1997.

MENEZES, L. J. J. M. O ensino bilingue em Moçambique: entre a casa e a escola. Tese (Doutorado). Salvador: UFB, 2013.

NGUNGA, A. Interferências de Línguas Moçambicanas em Português falado em Moçambique. Revista Científica da Universidade Eduardo Mondlane, Série: Letras e Ciências Sociais, v. 1, n. 0, p. 7-20. Moçambique, 2012.

NGUNGA, A. A intolerância linguística na escola moçambicana. Conferência sobre educação em Moçambique. Maputo, 2007.

PISSURNO, K. C. S. A concordância verbal de terceira pessoa do plural na variedade moçambicana do Português: uma abordagem sociolinguística. Dissertação (Mestrado em Língua Portuguesa) - Rio de Janeiro: Faculdade de Letras/UFRJ, 2017.

ROSÁRIO, L. A Língua Portuguesa como Factor de Desenvolvimento Nacional e Afirmação Internacional: que desafios? In: GONÇALVES, P.; CHIMBUTANE, F. S. (Org.). Multilinguismo e Multiculturalismo em Moçambique: Em direção a uma coerência entre discurso e prática. Moçambique: Alcance Editores, 2015. 
SITOE, B.; NGUNGA, A. Relatório do II Seminário sobre a Padronização da Ortografia de Linguas Moçambicanas, NELIMO - Centro de Estudos das Línguas Moçambicanas, Universidade Eduardo Mondlane, Maputo, 2000.

STERN, H. Fundamental concepts of language teaching. Oxford. OUP, 1983.

STROUD, C. Aquisição de língua segunda. In: GONÇALVES, P.; STROUD, C. (Org.). Panorama do Português oral de Maputo, v. I - Objetivos e Métodos. INDE - Cadernos de Pesquisa n. 22, p. 11-45. Maputo, 1997.

TIMBANE, A. A. Desafios do ensino do português em contexto multilíngue em Moçambique. Revista Travessias, v. 8, n. 2. Paraná: UNIOESTE, 2015.

TIMBANE, A. A. Que português se fala em Moçambique? Uma análise sociolinguística da variedade em uso. Revista Vocábulo, v. VII. São Paulo, 2014. 
